\title{
Prevalência, Mortalidade E As Principais Comorbidades Encontradas Nos Pacientes Em Choque Séptico Fatal Na Unidade De Terapia Intensiva.
}

\author{
Rocha, P.L.; Coelho, G.; Rhoden, M.; Teixeira, L.O.; Teixeira, V.N.K.;
}

Apresentador: Pablo Lima Rocha

\section{Resumo}

Introdução: O choque séptico pode ser considerado como um dos maiores desafios no manejo de pacientes criticamente enfermos, tendo elevadas taxas de prevalência e de mortalidade no Brasil e no mundo. Este estudo buscou dados sobre a prevalência do choque séptico e sua mortalidade em uma unidade de terapia intensiva (UTI) de um hospital geral na cidade de Pelotas/RS, bem como fatores associados presentes em pacientes que não sobreviveram a esta adversidade. Método: Estudo transversal e retrospectivo, tendo como banco de dados relatórios de janeiro a junho de 2014 do Comitê de Controle da Sepse do Hospital Universitário São Francisco de Paula - Pelotas/RS. Resultados: A prevalência do choque séptico na UTI estudada foi de $29,67 \%$, totalizando 105 casos durante o período. A taxa de mortalidade foi de $55,24 \%$, valor considerado abaixo da média quando comparado a outros estudos. Ao traçar o perfil destes pacientes que foram a óbito, encontramos que $54,17 \%$ eram do sexo masculino e tinham como média de idade 62,3 anos. As principais comorbidades encontradas foram neoplasia maligna, presente em $22,41 \%$ dos óbitos patologias do sistema nervoso central - acidentes vasculares isquêmicos e hemorrágicos ou traumatismos -, ocorrendo em 18,18\% diabetes mellitus
(DM) em 15,51\% e síndrome da imunodeficiência adquirida (SIDA) em 10,34\%. Outro dado pertinente de discussão é a procedência destes pacientes. A grande maioria, cerca de $56,10 \%$, foi proveniente do Pronto Socorro Municipal. Outros 29,27\% vieram do setor de clínica médica e $12,19 \%$ da cirúrgica, ambos do mesmo hospital. Conclusões: A mortalidade do choque séptico ainda apresenta taxas elevadas, mesmo em hospitais que apresentam um controle enérgico do seu tratamento. A taxa de mortalidade da unidade estudada pode ser considerada aceitável de acordo com diversos estudos, e este fato pode advir da realização do diagnóstico e conduta precoce, buscando o controle do foco infeccioso e o correto manejo durante a reanimação do paciente. Ainda que estes recebam tais cuidados, existem fatores que interferem na recuperação do paciente. Evidenciamos, ainda, que as principais patologias associadas ao choque séptico fatal foram neoplasia maligna, afecções do sistema nervoso central, DM e SIDA. Dessa forma, salienta-se que, além do manejo adequado, ágil e precoce, as comorbidades encontradas em pacientes em choque séptico devem ser avaliadas e apropriadamente conduzidas a fim de diminuir possíveis complicações irreversíveis.

\section{Referência:}

Rocha, P.L.; Coelho, G.; Rhoden, M.; Teixeira, L.O.; Teixeira, V.N.K.;. Prevalência, Mortalidade E As Principais Comorbidades Encontradas Nos Pacientes Em Choque Séptico Fatal Na Unidade De Terapia Intensiva.. In: II Congresso Brasileiro de Medicina Hospitalar - II CBMH [= Blucher Medical Proceedings, vol.1, num.5] São Paulo: Editora Blucher, 2014. p.41 DOI 10.5151/medpro-II-cbmh-034 